\title{
Nas tramas do sub-emprego: precarização do trabalho dos catadores de recicláveis na dinâmica territorial de Bragança Paulista (SP)
}

\author{
In the plot of self-employment: the degeneration \\ of labor relations from recycable self-employees \\ in the territorial's dynamic of Bragança Paulista (SP)
}

\section{Orlando Leonardo Berenguel}

Professor da Universidade Presbiteriana Mackenzie e Faculdade de Atibaia e coordenador do Programa de Pós-graduação da Faculdade Gerencias Barão de Jundiaí (SP)

\section{oberenguel@hotmail.com}

\section{Resumo:}

Este artigo parte da idéia de que a crise ambiental urbana e a excessiva geraçáo de resíduos sólidos tem motivado uma série de conflitos e disputas no que tange ao lixo urbano. Procura compreender o trabalho de catadores de recicláveis em Bragança Paulista - SP. O catador de recicláveis é tratado neste estudo com sujeito que depende dos resíduos para a sua sobrevivência. Discute-se a existência de uma precarização das relaçóes de trabalho tais como: falta de estrutura física, equipamentos, registro em carteira de trabalho. Pode-se perceber que o catador nem sempre é um habitante, ou seja, não tem o devido reconhecimento de cidadania. É constantemente tomado por um indivíduo marginal, ou seja às margens das relações estabelecidas nas cidades, em que os direitos não são assegurados mas os deveres devidamente cumpridos.

Palavras-chave: Catador; Relaçóes de trabalho; Exclusão social

\section{Abstract:}

This article starts from the idea that the environmental crisis and excessive urban solid waste generates several conflicts in relation to urban wastes. This study tell us about the work from self-employees of recyclables in Bragança Paulista - SP. Those self-employees looking for garbage are treated in this study as a people that depends on it for their very survival. It discusses the degeneration of existent autonomous labor relations, such as lack of physical infra-structure, equipments and unregistered labor. You can also see that they are not considered inhabitant, or has no recognition from any appropriated dweller in the city. They are often taken as marginal people which the civil rights are not granted but the obligations accomplished.

Keywords: Self employees; Labor relations; Social exclusion 
7 reciclagem do lixo urbano tornou-se uma atividade emergente a partir do crescimento dos movimentos de preservaçáo ambiental. Apa- rentemente, falar em reciclagem levaria às suas indiscutíveis vantagens ambientais, mas não ocorre o mesmo ao deslocar-se o olhar para a força de trabalho, que faz do lixo uma alternativa de renda para a sobrevivência.

Dos coletores coloridos à prática realista, existe uma grande legião de homens excluídos do mercado de trabalho, que não têm a menor percepção dos problemas ambientais que o globo experimenta e que podem ser considerados, agentes de transformação, uma vez que efetivamente abastecem o mercado da reciclagem, dando um novo destino aos resíduos.

Este estudo tem origem a partir de observaçóes do trabalho do catador de recicláveis no município de Bragança Paulista, situado no interior do Estado de Sáo Paulo, com aproximadamente 150.000 habitantes, de acordo com o SEADE (2008). O município está aproximadamente a $15 \mathrm{~km}$ da divisa com o Sul de Minas Gerais, próximo da confluência de duas grandes e importantes rodovias, a Dom Pedro I e a Fernáo Dias, e do Complexo Cantareira de abastecimento de água. Fica a 70 km da cidade de São Paulo e a 65 km da Região Metropolitana de Campinas.

A escolha pelo local de estudo se deu em função das características do processo migratório e pela dinâmica territorial. Em 2006, Bragança Paulista, a exemplo de outros municípios brasileiros, deu início a um projeto que resultaria em uma cooperativa de catadores. $\mathrm{O}$ projeto consistia em identificar, através da área de assistência social do município, pessoas interessadas em trabalhar como catadores de recicláveis ou que já apresentassem uma experiência com este trabalho. Aparentemente as idéias do projeto eram simples, ou seja, organizar e ordenar os trabalhos de indivíduos, num propósito coletivo para a geração de renda. Em dois anos de funcionamento do projeto, percebeu-se que o universo dos catadores é muito mais rico e complexo do que se podia imaginar.

Além da rudeza do trabalho, os catadores enfrentam muitas discriminações, bem como o pouco caso das autoridades. Muitas vezes são confundidos com preguiçosos, oportunistas, vândalos, enquanto na verdade são competidores aguerridos em busca do lucro, são espertos negociadores, produtores incansáveis, e, sobretudo, são pais, mães e avós, que provêm o sustento de muitos indivíduos de seu núcleo familiar.

A precarização do trabalho do catador se dá pela falta de condiçôes e de segurança do trabalho e principalmente pela baixa remuneraçáo do resultado da catação, inclusive quando os resíduos coletados são utilizados como moeda de troca, seja por alimento ou por aguardente.

O aumento da precarização das relaçóes de trabalho dos catadores de recicláveis de Bragança Paulista está calcado na política de atrair novos eleitores para a fixarem-se no município com a promessa de moradia e alimentação, o que trouxe grandes custos sociais no que se refere ao acesso aos serviços urbanos. Muitos desses migrantes não foram absorvidos pelo mercado de trabalho local e tiveram de ingressar no "mercado do lixo". Esses migrantes são em sua maioria das regióes norte e nordeste do país e chegaram primeiramente à cidade de São Paulo em busca de uma vida melhor; ao se defrontaram com as pressóes da grande metrópole, deslocam-se para cidades próximas que pudessem abrigá-los. Este processo arrasta, por natureza, o aumento do desemprego local, da violência e da própria falta de oportunidades, agravado pela baixa qualificaçáo do trabalhador 
e pelas políticas municipais, como o excessivo assistencialismo promovido pelo poder público e por entidades religiosas.

Nesse sentido, é fácil entender que muitos conflitos se estabelecem pela disputa dos recursos gerados pelo lixo, agravados pela ausência de uma política municipal minimamente adequada. A luta dos catadores pelo uso do lixo urbano demonstra também os atuais processos de segregaçáo espacial, apoiados na competitividade estabelecida a partir da livre iniciativa de sobrevivência, e é essa precarização do trabalho e das condiçôes de vida que justificam este estudo. Apesar do tom assistencialista e do discurso de inclusão que envolve o tema, o catador é força de trabalho.

\section{A PRECARIZAÇÃo DAS RELAÇÓES DE TRABALHO}

Desde os primórdios da humanidade, quando o homem passou a se organizar em grupos específicos dados por identidade familiar, o trabalho ganha consideraçóes próprias. Na visão marxista o trabalho é toda e qualquer transformação da natureza de forma consciente, podendo, portanto, ser desempenhado apenas pelo homem, que transforma seu ambiente natural, de maneira objetiva.

Com a evoluçáo do trabalho fomentada pela Revolução Industrial, a natureza ganha uma nova interpretação, ou seja, o conceito de meio ambiente. Isto se dá devido à maneira pela qual o homem transformou este meio ambiente, não só no sentido extrativista, mas também, e principalmente, no sentido ocupacional.

Existir e coexistir são situações diferentes, mas não excludentes. Entretanto, a coexistência supóe a união de interesses satisfeitos para que a sobrevivência possa ser alcançada. Isto, evidentemente, implicará no fato de que náo se pode existir efetivamente sem coexistir, ou seja, a satisfação dos interesses do grupo é aquilo que garantirá a vida como um todo.

Ora, para que a satisfação dos interesses ocorra é fundamental que a existência, através da coexistência, se faça via trabalho, que é a transformação consciente da natureza, ou meio ambiente.

Considerando então o trabalho como elemento transformador da natureza, pode-se dizer que a atividade dos catadores também, de certa forma, transforma a natureza esculpida pelas demandas de convívio social, sendo que, nos tempos atuais, a principal delas é o acúmulo de resíduos, ou seja, o lixo. Isto é dado pelo desenvolvimento tecnológico aliado a padróes culturais e de convívio, o que caracteriza a cidade moderna pela visão de "natureza construída" através das exigências do trabalho propriamente dito.

A abordagem das transformações do "mundo do trabalho" ocorridas na segunda metade do século XX requer considerar o processo de reestruturaçáo produtiva, provocado pelas relaçóes de trabalho e as formas de organização dos trabalhadores, como subsídio das transformaçóes da produção e do mercado. (MARINHO, 2005: 24)

É a fase fordista do trabalho, no início do século XX, baseada na produção de mercadorias em série (massa), que buscava uma produção mais homogeneizada e hierarquizada, que possibilita entender este padrão produtivo, que teve como elementos fundamentais o trabalho parcelar e fragmentado e a decomposição das tarefas, que reduziam a ação às suas operaçôes mínimas, ou seja, a separação entre execução e planejamento, o aumento do controle sobre o trabalhador, a cronometragem de cada movimento do operário na execução das operaçóes e a rotinização do trabalho. (ANTUNES, 1995)

A mesma base analítica pode ser aplicada ao trabalho dos catadores, uma 
vez que seu interesse pela atividade se dá por conta dos valores monetários relativos aos elementos oriundos da catação, ou seja, cada material terá um valor próprio e por isso, dependendo deste mesmo valor de venda/repasse/troca, será mais disputado neste contexto. Assim, o valor econômico terá uma importância muito maior do que necessariamente os impactos ambientais provocados pelo lixo, ou seja, a catação não será desenvolvida por conta da consciência em relaçáo aos benefícios da reciclagem, mas sim pela possibilidade de sobrevivência.

Assim, pode-se afirmar que o trabalho destes catadores influenciará a dinâmica social pela qual se dá o convívio dos mesmos com as classes diferenciadas que habitam a mesma arena de conflito.

Mattoso (1999), ao abordar a precarização do trabalho, afirma que tal precarizaçáo ocorre através da falta de carteira assinada e do trabalho independente (por conta própria) sem contribuição previdenciária, e sem direito a aposentadoria. Esta precarização também pode ser caracterizada pelo aumento do trabalho por tempo determinado sem renda fixa, em tempo parcial, também conhecido como "bico", o que, aliás, cresce nos grandes centros, porque os honorários relativos às contrataçóes trabalhistas (que caracterizam o trabalho formal) tornam-se exacerbados para o empregador, gerando com isso novas atividades, "bicos", que possam garantir a sobrevivência.

Como demonstrado por Mattoso (1999) a precarização pode ser identificada pelo aumento do trabalho por tempo determinado, sem renda fixa, em tempo parcial, enfim, pelo que se costuma chamar de "bico". Em geral, a precarização é identificada com a ausência de contribuição à Previdência Social e, portanto, sem direito à aposentadoria.

Pode-se ainda concluir que o Estado deveria fiscalizar mais intensamente tais relaçóes informais, contudo, esta fiscalização não deve ser apenas punitiva, uma vez que tais atividades ocorrem por necessidade de sobrevivência, mas sim, promotora de novas e mais conscientes açóes que possam garantir e assegurar a estabilidade de uma sobrevivência digna.

A precariedade do trabalho mal remunerado, pouco reconhecido, provoca um sentimento de inutilidade no trabalhador e gera instabilidade e ameaça de desemprego, restrição aos direitos sociais e falta de perspectivas de crescimento profissional, tanto em relação ao setor informal, quanto em relação à classe trabalhadora em geral. (CONCEIÇÃO, 2003)

Segundo Piccinini (2004), a difusão das formas precárias está ligada à flexibilidade quantitativa e à redução de custos pelo recurso a vínculos contratuais instáveis, e à substituição de contratos de trabalho por contratos comerciais. A autora cita, como tipos de flexibilidade quantitativa, a terceirização e a subcontratação, trabalho em domicílio, rede de empresas, cooperativas de trabalho, trabalho temporário, trabalho em tempo parcial, trabalho em tempo compartilhado, suspensão temporária do contrato de trabalho e estágios. Já para Antunes (1995), essa precarização do trabalho está em plena sintonia com o modo de produção capitalista, que identifica o homem como um número apenas, não objetivando seus valores pessoais e sua real condição humana, importando tão somente o acúmulo de riquezas. Daí poder-se deduzir que a consciência do catador em relação ao meio ambiente se dê da mesma maneira, ou seja, importa-lhe a sobrevivência e não o meio ambiente como espaço de coexistência.

$\mathrm{Na}$ visão de Medeiros e Macedo (2006), conclui-se que atualmente há uma crise do trabalho assalariado nos moldes típicos do sistema capitalista, expressa nas 
seguintes formas: aumento do desemprego estrutural e precarização do trabalho, exclusão de trabalhadores do mercado formal de trabalho e exclusão do convívio social.

As autoras apontam que as conseqüências psicossociais advindas da crise atual do trabalho assalariado são perversas, pois atacam os alicerces da identidade do ser humano. Elas distinguem a relação entre sofrimento e emprego, e sofrimento e trabalho. A primeira está ligada à crise do trabalho assalariado e ao desempregado, e a segunda diz respeito aos trabalhadores que continuam a trabalhar. Assim, esclarecem que também existe o sofrimento dos que trabalham, que temem não satisfazer, não estar à altura das imposiçóes da organização do trabalho; imposiçôes de horário, de ritmo, de formação, de informação, de aprendizagem, de nível de instrução e de diploma, de experiência, de rapidez de aquisição de conhecimentos teóricos e práticos e de adaptação à "cultura" ou à ideologia organizacional, às exigências do mercado, às relaçôes com os clientes, os particulares ou o público, etc.

Conforme Antunes (1995), Mattoso (1999) e Souto de Oliveira (2004), fazem parte das transformaçóes no mundo do trabalho: o declínio do setor secundário na absorção de mão-de-obra e a expansão do setor terciário; a retração do salário formal; a flexibilização das relaçóes contratuais de trabalho, redundando em perda ou subtração de direitos do trabalho e, conseqüentemente, num menor ou mesmo ausente grau de proteção social; as mudanças nos requerimentos feitos ao trabalhador sob a égide da "empregabilidade", que se traduzem por maior grau de escolarização formal e por uma crescente exigência de atributos, tais como polivalência, autonomia, iniciativa e competitividade; a informalização e precarização das relaçóes de trabalho; a manutenção/agravamento das desigualdades de rendimento e a dilataçáo das margens de pobreza.

Partindo das transformaçôes no mundo do trabalho, pode-se inferir que é crescente e expressivo o número de trabalhadores que se encontram sob condiçôes que configuram exclusão social, como é caso dos catadores.

No entendimento da sociedade contemporânea, o conceito de exclusão é crucial, visto que as transformaçóes do mundo do trabalho, principalmente as advindas das transformaçóes do modo de produção, modificaram o cenário das relaçôes sociais até entấo vigentes.

Medeiros e Macedo (2006), ao questionarem a inclusão social, identificam que muitos autores tomam como referência principal para esta situaçáo a questão do desemprego, concluindo, assim, que estar desempregado significaria não estar integrado, e levantam as seguintes questôes: O que dizer daqueles que trabalham sem, contudo, terem um emprego? Seria o desemprego o ponto de partida para a análise da inclusão/exclusão social de uma parcela de trabalhadores que desempenham trabalhos como a catação de material reciclável?

A adoção exclusiva desse ponto de partida levaria ao ofuscamento de artimanhas da exclusão social. Por trás de formas aparentes de inclusão social, existem formas sutis de exclusão, as quais conduzem a uma aparente inclusão, que camufla uma exclusão, entendida como inclusão perversa. Assim, pode-se concluir que não há exclusão antes de uma inclusão.

Portanto, conforme Spossati (1996), a idéia de exclusão social supóe uma lógica que preside um padrão de relaçôes em uma sociedade que, ao mesmo tempo, inclui e exclui por meio de um conjunto de valores que a orienta. Neste caso específico dos catadores de Bragança Paulista, a exclusão social é evidente. 


\section{A (RE)OrganizaÇấo do EMPREgo URbano}

O processo de crescimento da população urbana é muito mais perceptível em países em desenvolvimento, indicando que há necessidade de levar-se em consideração variações, fatores e condições diferentes que presidem a formação da populaçáo urbana - de um lado a situação de origem do urbano, e de outro os fenômenos atuais que decorrem das características demográficas e econômicas dos países em desenvolvimento. (SANTOS, 1981: 21-2)

Milton Santos (1996) aponta a importância de se analisar a crescente urbanização como o resultado de agravamentos de problemas sociais e econômicos. Assim, analisar o crescimento urbano de Bragança Paulista é também analisar estes agravamentos, principalmente os que são de interesse dos "homens lentos". Essas análises, de modo geral, são desligadas da realidade social como um todo, são tratadas como microproblemas sem se reconhecer a sociedade em movimento, seja condicionada pela vulnerabilidade que os modelos capitalistas imprimem, seja pela eterna tentativa de se comparar o processo de urbanismo de países em desenvolvimento com países europeus. Este processo acaba por distanciar a verdadeira interpretação que se possa imprimir na análise do "território usado", tentando compreendê-lo como um espaço vivido, espaço real, e não apenas como um modelo trazido de países desenvolvidos.

Ao se estudar a urbanização dos países em desenvolvimento, é perceptível o número de grandes cidades, especialmente na América Latina. Este fenômeno deve-se principalmente à organizaçáo das forças produtivas e sua concentração em certos pontos do território, em contraponto ao aumento do consumo. (SANTOS, 1996)

Fatores como esses não podem ser desprezados em uma análise do espaço urbano de Bragança Paulista, principalmente pela proximidade dos grandes centros que serviram e servem ao desenvolvimento das forças produtivas, gerando grandes cidades como as da região da Grande São Paulo e as da Região Metropolitana de Campinas, ambas as regiôes com fortes tendências para o atendimento dos mercados internacionais.

A interpretação das forças produtivas deve ainda considerar as inter-relaçôes entre diferentes variáveis, que levem a um enfoque analítico, considerando a divisão do trabalho. No caso de Bragança Paulista, essas variáveis estão expressas nas atuais práticas sócio-espaciais, que aparecem como uma solução da estagnação da força produtiva formal (o trabalho da indústria, comércio e serviços). Estas práticas sócio-espaciais nascem também da relação de consumo e da relação com o meio ambiente, principalmente, quando resíduos e outros materiais recicláveis, antes sem destinação, ganham "status" de matéria-prima e, conseqüentemente, importância para os interesses industriais.

Em contribuição ao entendimento destas práticas pode-se destacar o pensamento de Milton Santos quando diz que:

A cada movimento, possibilitado pelo processo da divisão do trabalho, uma nova geografia se estabelece, seja pela criação de novas formas para atender as novas funçóes, seja pela alteração funcional das formas já existentes. Daí a estreita relação entre divisão social do trabalho, responsável pelos movimentos da sociedade e a sua repartição espacial. (SANTOS, M., 1996) 
Através desses conceitos é possível entender que a atual função de catadores de sucatas, papéis e outros resíduos reinsere trabalhadores na força de trabalho. Cabe destacar que a divisão do trabalho social propóe diversamente assumir as diferentes porçôes de natureza, ou seja, dá a uma paisagem a condiçáo de espaço produtivo. Para Milton Santos, (1996: 60) "espaço global se define pelo conjunto de lugares empreendidos como porçóes do espaço produtivo e como lugar de consumo".

Segundo Moraes (1999), a natureza extremamente dinâmica dos processos econômicos e sociais integrados, em um país como um todo e em cada regiáo, faz com que mude constantemente o padrão da divisão territorial do trabalho. Por outro lado, o aumento da eficiência da produçáo social depende amplamente, não apenas do modelo atual existente, como também dos futuros padrôes de distribuição das forças produtivas nas regiôes econômicas do país. A cada momento da divisão do trabalho, a sociedade total se redistribui, através de suas funçóes novas e renovadas, no conjunto de formas preexistentes ou novas.

Com a fixação de capital estrangeiro, através das empresas transnacionais, passou-se a exigir uma divisão do trabalho com características internacionais, forçando adaptaçóes e o aparecimento de especificidades. Essa divisão desloca a atribuição de um valor determinado a cada forma e a todas as formas, através da redistribuição de funçóes. A divisão internacional do trabalho explica a seletividade espacial na realização de funções, mediante critérios como a necessidade, a rentabilidade e a segurança de uma dada produção. A divisão interna do trabalho mostra o movimento da sociedade, a criação e os reclamos de novas funçóes, e a maneira como essas funções são abrigadas pelas formas preexistentes ou novas.

Os problemas do emprego sempre estiveram associados às especificidades da estrutura produtiva das economias nacionais periféricas. Estas apresentaram tanto um pequeno grau de diversificação e integração vertical, quanto uma heterogeneidade estrutural dada pela incorporação desigual do progresso técnico pelos diversos setores econômicos. Nessa conjunçáo de fatores, o ritmo de acumulação de capital mostrou-se insuficiente, embora rápido, explicando, em última instância, a não absorção pelo mercado de trabalho de uma força de trabalho que se mostrou excedentária. (ALVES, 2000)

De acordo com o Programa Regional de Emprego para América Latina e o Caribe (PREALC), da Organização Internacional do Trabalho (OIT), um fator comum entre os países latinos é que, apesar do crescimento econômico, o nível de empregos mantém-se insuficiente e sem uma melhoria na distribuição de renda, revelando um cenário em que o enorme subemprego agrícola coexistia com um crescimento expressivo da população urbana, advindo de um forte fluxo migratório campo-cidade, gerando uma população marginal localizada no entorno das grandes cidades. (PREALC, 1990)

O mesmo documento indica também que o crescimento do emprego industrial e dos serviços funcionais, desde a década de 50 , foi insuficiente para absorver toda a população economicamente ativa urbana, apesar do crescimento da produção. Além do crescimento vegetativo da população rural e do subemprego no campo, o fluxo migratório teria sido norteado pelo fato de o salário urbano da máo-de-obra pouco qualificada ser superior àquele que os migrantes podiam ganhar no meio rural.

A complexidade da situação ocupacional não pode ser analisada apenas através da taxa de desemprego. Ao contrário, é necessário entendê-la como um 
"estrato de distintas formas de subutilização da força de trabalho", o que pode assemelhar-se a um iceberg que deixa à vista o desemprego aberto, mas que, na realidade, significa muito mais: o subemprego, tanto rural quanto urbano. (PREALC, 1995) O crescimento econômico não garantiu por si só um maior nível de emprego nem uma melhor distribuição de renda. Em função disso, o número de pessoas disponíveis e de famílias que vivem em condiçóes de pobreza, em lugar de diminuir, tem-se mantido e inclusive apresentado tendências a um real aumento. (PREALC, 1990)

Com isso, verificam-se dois setores: um, de menor dimensão ocupacional, que incorpora o progresso técnico e tem altos níveis de produtividade; outro, de maior magnitude, que é ocupado pelos estratos intermediários, com correspondentes níveis de renda e produtividade. Da perspectiva da estrutura de emprego, estes dois setores constituem um "mercado de trabalho organizado". Eles produzem um conjunto de atividades econômicas norteado pela racionalidade econômica e com um grau razoável de organização, que tem fundamento na mesma evoluçáo histórica.

No entanto, estes dois setores econômicos, de distintos níveis de produtividade, que configuram uma estrutura ocupacional "organizada", mostraram-se, na verdade, incapazes de incorporar toda a força de trabalho em idade produtiva para maior participaçáo na atividade econômica; desse fato resulta um excedente de mão-de-obra que não encontra ocupação naqueles setores econômicos. Esta sobreoferta de trabalho, ou fica desempregada, ou cria estratégias de sobrevivência nas novas atividades que ela mesma ajuda a conformar nos conglomerados urbanos.

Esta estrutura produtiva do mercado de trabalho aponta para a existência dos problemas de emprego em termos do funcionamento do mercado de trabalho diferenciado, seja na área rural, seja na área urbana. Assim, uma vez assumida a hipótese da heterogeneidade da estrutura produtiva, distinguem-se dois setores diferenciados no mercado de trabalho urbano: um é o mercado formal, que pelo lado da oferta gera ocupaçóes em empresas organizadas, e o outro é o mercado informal que, por sua vez, está relacionado às atividades de baixo nível de produtividade para trabalhadores independentes ou por conta própria, e para empresas muito pequenas, não organizadas institucionalmente.

Com efeito, pode-se associar o setor informal urbano àquele mercado de trabalho no qual se encontram os problemas de baixa produtividade e das baixas rendas que recebem as pessoas que estão nele ocupadas. Postula-se aqui, portanto, uma correlação entre a pobreza e a forma de inserção no mercado de trabalho. (PREALC, 1999)

Admite-se que a migração cumpre um papel fundamental, contribuindo fortemente para gerar o excedente de mão-de-obra nas cidades, que ao não ser absorvido pelas atividades do setor moderno, dá origem ao setor informal. (PREALC, 1990) É evidente que este fato tem correspondência com os processos históricos verificados na região bragantina.

Assim, o estilo de desenvolvimento das economias atrasadas concentra no setor industrial, ao lado dos serviços funcionais, e particularmente, na indústria de transformação, uma base produtiva moderna, mas incapaz de absorver todo o aumento da população ativa urbana. Desta forma, a relação entre migração/urbanização e setor informal urbano tem uma importância decisiva na explicação do setor informal urbano, ao marcar a urbanização e a estrutura das ocupaçôes nas cidades através do excedente de mão-de-obra. 
O problema do setor informal e do subemprego tende a diminuir na hipótese do prosseguimento da industrializaçáo e do desenvolvimento, à medida que a economia se desenvolve. Há uma tendência para reduzir a incidência do setor informal, visto que, hipoteticamente, de acordo com o tamanho das cidades, menor será a incidência do emprego informal no mercado de trabalho urbano. (PREALC, 1990)

Em síntese, de uma conjunção da dinâmica dos fluxos migratórios e da incapacidade do setor moderno da economia de gerar oportunidades ocupacionais no ritmo exigido para absorver a população ativa urbana, surge um novo "setor tradicional" em termos de produtividade e renda. (PREALC, 1978) Este setor, denominado setor informal, em contraposição ao setor moderno e organizado da economia, é o mecanismo através do qual procuram sobreviver os migrantes que não encontram emprego na área organizada do mercado de trabalho. É o excedente estrutural de mão-de-obra que cria o setor informal urbano, segundo sua própria lógica: gerar circuitos de sobrevivência, através de um amplo segmento de atividades econômicas, onde seus integrantes se auto-empregam na produçáo de bens e serviços em pequena escala e com baixos níveis de produtividade, com os quais obtêm uma pequena renda, ou seja, a renda informal.

Fica evidente que o setor informal urbano está implicitamente colocado como um "setor de ajuste" para as economias, porque faz parte do desenvolvimento econômico, embora seus trabalhadores sejam caracterizados como socialmente pobres, com menor grau de instrução e em faixas etárias que incluem tanto os mais jovens quanto os mais velhos.

São as características dos migrantes e a insuficiente disponibilidade de oportunidades de emprego no setor formal urbano que determinam que o setor informal tenda a ser um receptáculo para os migrantes rurais que aportam nas cidades. O setor informal é visto como parte de uma dicotomia em que seus ocupantes produzem bens e serviços que em essência não são demandados pelo setor formal. (PREALC, 1978)

A evidência de que, pelo menos por alguns períodos, os migrantes recentes e antigos passavam pelo emprego informal deu origem ao senso comum de que $o$ setor informal é a "porta de entrada" ao mercado de trabalho urbano.

\section{O TRABALHO DOS CATADORES E A EXCLUSÃo SOCIAL}

Birbeck (1978) denomina os catadores de "self-employed proletarians", pois, segundo o autor, o auto-emprego não passa de ilusão. Os catadores se autoempregam, mas, na realidade, eles vendem sua força de trabalho à indústria da reciclagem, sem, contudo, terem acesso à seguridade social do mundo do trabalho.

A rotina diária do catador é exaustiva e realizada em condiçôes precárias, conforme afirma Conceição (2003):

Muitas vezes, ultrapassa doze horas ininterruptas; um trabalho
exaustivo, visto as condiçóes a que estes indivíduos se subme-
tem, com seus carrinhos puxados pela tração humana, carre-
gando por dia mais de 200 quilos de lixo (cerca de 4 toneladas
por mês), e percorrendo mais de vinte quilômetros por dia, sen-
do, no final, muitas vezes explorados pelos donos dos depósitos
de lixo (sucateiros) que, num gesto de paternalismo, trocam 
os resíduos coletados do dia por bebida alcoólica ou pagamlhe um valor simbólico insuficiente para sua própria reprodução como catador de lixo. (CONCEIÇÃO, 2003: 34)

Os catadores catam e separam do lixo o material reciclável numa quantidade que seja suficiente para vender. O comércio dos materiais recicláveis, entre os catadores e as empresas de reciclagem, geralmente passa pela mediação dos atravessadores, chamados de sucateiros.

Estes intermediários recebem o material coletado, pesam e estabelecem o preço a ser pago aos catadores. Em seus depósitos, os sucateiros vão acumulando os materiais, prensando-os em fardos, até conseguirem uma quantidade que viabilize o transporte para as indústrias de reciclagem.

$\mathrm{Na}$ região Sudeste, um dia de trabalho rende aos catadores de dois a cinco reais, dependendo da quantidade e do tipo de material que recolhem. (CEMPRE, 2008)

Para Carmo (2005), os catadores desconhecem completamente os aspectos que envolvem a logística do processo de reciclagem, desconhecimento, muitas vezes, atribuído ao baixo nível de escolaridade. Carmo (2005) e Conceição (2003) concordam que esse pouco conhecimento do circuito da reciclagem é um forte impedimento para que catadores obtenham ganhos melhores nessa atividade.

Já para Viana (2000), a existência dos atravessadores pode ser explicada por dois fatores principais: primeiro, pela "dificuldade de locomoção" dos catadores de lixo para entregar o material nas indústrias de reciclagem e, segundo, pelas vantagens que esse sistema oferece às indústrias.

Dessa forma, Leal et al. (2002) concluíram que o catador de material reciclável participa como elemento base de um processo produtivo bastante lucrativo; no entanto, paradoxalmente, trabalha em condiçóes precárias, subumanas e não obtém ganho que lhe assegure uma sobrevivência digna.

Conceiçáo (2003) e dados do IPT (2003) relacionam o crescimento do número de catadores de materiais recicláveis com as crescentes exigências para o acesso ao mercado formal de trabalho, e também ao aumento do desemprego. Para esses autores, alguns trabalhadores da catação constituem uma massa de desempregados que, por sua idade, condição social e baixa escolaridade, não encontram lugar no mercado formal de trabalho.

Para que o indivíduo possa ser considerado incluso ou excluso é necessário reconhecer as dinâmicas que acontecem dentro do território a que pertence. Exclusão pela inclusão não seria inadaptação, ao contrário, é adaptação à exclusão social; a exclusão, para se repor, precisa ancorar-se no sentimento de pertencimento social e criar o sentimento de pertencimento ou inclusão nos seus sujeitos. Dessa forma, as autoras afirmam que "é no sujeito que se objetivam as várias formas de exclusão (...) é o indivíduo que sofre, porém, esse sofrimento não tem a gênese em si, e sim, em intersubjetividades delineadas socialmente". (MEDEIROS \& MACEDO, 2006)

O caráter excludente do trabalho do catador interfere na imagem que o mesmo faz de si, como identificado nas conversas com os catadores de Bragança Paulista. Assim, o trabalho com o lixo interfere tanto na identificação do catador com o seu trabalho como no reconhecimento da sociedade pelo trabalho desempenhado. Observando-se o verbo catar em sua definição mais 
básica, nota-se que este faz referência ao ato de pegar, tomar para si aquilo que outros desprezaram. Por esta ótica, verifica-se que o descaso com a atividade da catação propriamente dita, já é, em si mesma, preconceituosa em relação ao ato desenvolvido enquanto manutenção da sobrevivência.

Entretanto, a mídia em geral, alguns estudiosos e instituiçóes de diversos setores divulgam que a catação constitui uma possibilidade de inclusão social de uma parcela de trabalhadores. Mas, qual a qualidade dessa inclusão? Seria o fato de estar trabalhando, não importa em quê e como? Isso já é uma garantia de inclusão social? $\mathrm{O}$ fato de conseguirem garantir meios para a sua sobrevivência e a de seus familiares seria sinônimo de inclusão? Seria de fato uma inclusão ou mais uma forma de exclusão transmutada em inclusão?

Sob o ponto de vista de Medeiros e Macedo (2006), tornar-se catador é sentido como fonte de dignidade e modo legítimo de obter renda. É uma atividade que faz do excluído um trabalhador inserido no mundo do trabalho, diferenciando-o do mendigo ou vadio. Contudo, a inclusão desses catadores ocorre de forma perversa.

Dessa maneira, pode-se inferir que o catador de materiais recicláveis é incluído ao ter um trabalho, mas excluído pelo tipo de trabalho que realiza: trabalho precário, realizado em condiçóes inadequadas, com alto grau de periculosidade e insalubridade; sem reconhecimento social, com riscos, muitas vezes, irreversíveis à saúde e com a ausência total de garantias trabalhistas.

Uma análise prematura da situação dos catadores de materiais recicláveis levaria a uma conclusão equivocada: a de que são incluídos socialmente. Entretanto, por trás de formas aparentes de inclusão social, existem formas sutis de exclusão que conduzem à inclusão perversa. $\mathrm{O}$ que se observa é uma condição oposta, na qual o trabalho da catação é quase sempre desfavorável ao trabalhador. Conforme estudos mencionados nesta pesquisa, o trabalhador-catador é exposto a riscos de saúde, preconceitos sociais, ausência dos direitos trabalhistas e outras condiçóes que são extremamente precárias, tanto na informalidade de trabalho quanto na remuneração. Além disso, os catadores não têm acesso à educação e ao aprimoramento técnico.

Paradoxalmente, mesmo ocorrendo nas condiçôes demonstradas, que são bastante adversas, a catação possibilita a sobrevivência de muitos trabalhadores que se encontravam excluídos e sem alternativas para a subsistência. Lentamente, os catadores buscam se organizar em cooperativas e associaçóes, visando melhores condições de trabalho.

\section{CONSIDERAÇÓES FINAIS}

Não se pode deixar de descartar que ao falar-se do trabalho da catação, as pesquisas esbarram nos sérios problemas oriundos do acúmulo residual urbano. Sabe-se que hoje a produção de lixo é muito maior do que a real capacidade que os poderes públicos constituídos, tais como, prefeituras, subprefeituras, associaçóes de moradores, etc., possuem para lidar de maneira ecologicamente correta com a questão. É óbvio que o aumento das necessidades de consumo, ampliadas por ferozes estratégias de marketing, geram uma quantidade de resíduos que serão dispostos nos espaços habitáveis sem condiçóes minimamente adequadas para que o conceito de meio ambiente possa prevalecer.

Contudo, este acúmulo residual é que garante a sobrevivência de indi- 
víduos que não tiveram inserção no exíguo e exigente mercado de trabalho.

$\mathrm{O}$ conceito de meio ambiente só existe se direcionado à sobrevivência humana. Ao falar do meio ambiente ligado às questôes urbanas, automaticamente é necessário fazer referência a um contexto em que o homem seja o gerador daquilo que ele próprio irá descartar, ou seja, o lixo.

Pode-se perceber também que este indivíduo-ator-catador nem sempre é um habitante, ou seja, não tem o devido reconhecimento pertinente a um habitante urbano. É freqüentemente tomado por um indivíduo marginal, compreendendo-se por este termo, alguém que esteja à margem das relaçóes estabelecidas na cidade, em que os direitos são assegurados e os deveres devidamente cumpridos.

Assim, o que se roga com este estudo é a adoção de políticas públicas e práticas sociais, menos idealizadoras e sim mais reais, que possam compreender o catador de recicláveis como indivíduo que pode viver dignamente do seu trabalho e que seja ainda, reconhecido o valor deste mesmo trabalho para o meio ambiente.

\section{REFERÊNCIAS BIBLIOGRÁFICAS}

ALVES, Giovani. O novo (e precário) mundo do trabalho. São Paulo: Boitempo, 2000.

ANTUNES, R. Adeus ao trabalho? - Ensaio sobre as metamorfoses e a centralidade do mundo do trabalho. 6a ${ }^{a}$ ed. Campinas: Cortez, 1995.

BIRBECK, C. Self-employed proletarians in an informal factory: the case of cali's garbage dump. World Development. 6( 9-10),1173-1185, 1978.

BORTOLOZZI, Arlêude; PEREZ, Archimedes. "Crise ambiental da modernidade e a produção do espaço - lugar do não cidadão". Boletim Paulista de Geografia, n.76, p. 7-21.

BORTOLOZZI, Arlêude. "Patrimônio cultural em território urbanizado e a reconstrução das cidades contemporâneas: caminhos e possibilidades da educação patrimonial”. X Colóquio Internacional de Geocrítica. Barcelona, 2008.

CÂMARA MUNICIPAL DE BRGANÇA PAULISTA. Trajetórias e Identidades. 1974-2005.

CASTELLS, Manuel. A sociedade em rede, a era da informaçâo: economia, sociedade e cultura. $3^{a}$ ed. São Paulo: Paz e Terra, 2000.

CARMO, M. S. "A semântica 'negativa' do lixo como fator 'positivo' à sobrevivência da catação - Estudo de caso sobre a associação dos recicladores do Rio de Janeiro". In: Encontro Nacional da Associação Nacional de Pós-graduação em Pesquisa em Administração. ENANPAD, Brasília DF, 2005.

CONCEIÇÃO, Marcio M. Os empresários do lixo: um paradoxo da modernidade. Campinas: Editora Átomo, 2003.

DREIFUSS, Rene Armand. A época das perplexidades: mundializacão, globalização e planetarizacão: novos desafios. 3a . ed. Petrópolis: Vozes, 1999.

FUNDAÇÃO SEADE. Anuário Estatístico do Estado de São Paulo.

HARVEY, David. A justiça social e a cidade. São Paulo: Hucitec, 1980. . A condição pós-moderna. 2a ed. Sáo Paulo: Ed. Loyola, 1993.

INSTITUTO DE PESQUISA TECNOLÓGICA - IPT. Cooperativa de catadores de materiais recicláveis: guia para implantação. São Paulo: SEBRAE, 2003. 
LEAL, A.C.; et al. "A reinserção do lixo na sociedade do capital: uma contribuiçâo ao entendimento do trabalho na catação e na reciclagem". Revista Terra Livre, São Paulo, 18(19), 177-190, jul/dez, 2002.

MARINHO, M.C.N. "As transformaçôes no mundo do trabalho e suas implicações na formação do executivo”. 2005. 245 f. Dissertação de Mestrado (mestrado em psicologia) Universidade Católica de Goiás, Goiânia, GO.

MARX, Karl. O capital: crítica da economia politica. 18 a ed. Rio de Janeiro: Civilização Brasileira, 2001.

MATTOSO, J. O Brasil desempregado: como foram destruídos mais de 3 milhóes de empregos nos anos 90. São Paulo: ABRAMO, 1999.

MEDEIROS, L.F.R.; MACEDO, K. B. "Catador de material reciclável: uma profissão para além da sobrevivência." Psicologia \& Sociedade; 18 (2): 62 71; mai./ago. 2006

OIT. Programa regional del empleo para America Latina y Caribe - PREALC, 1978, 1990, 1995,1999.

PICCININI, V. C. Cooperativas de trabalho de Porto Alegre e flexibilização do trabalho. Sociologias, 6 (12), 68-105, 2004.

RODRIGUES, Arlete Moysés. Produção e consumo do e no espaço: problemática ambiental urbana. São Paulo: Hucitec, 1998.

. A cidade como direito. IX Colóquio Internacional de Geocrítica. Porto Alegre, jun. 2007.

SACHS, I. Ecodesenvolvimento - Crescer sem destruir. São Paulo: Editora Vértice, 1986.

SANTOS, Milton. Espaço e sociedade. São Paulo: Ed. Vozes, 1979.

. Manual de geografia urbana. São Paulo: Hucitec, 1981.

. Espaço e método. Sáo Paulo: Nobel, 1985.

. Metrópole corporativa fragmentada: o caso de Sáo Paulo. São

Paulo: Nobel, 1990.

. A urbanização brasileira. São Paulo: Hucitec, 1993.

. Tipografia. São Paulo: Hucitec, 1996.

- "Da política dos Estados à política das empresas". In: Cadernos da Escola do Legislativo. São Paulo, 1997.

. Por uma outra globalização: do pensamento único à consciência universal. 11 ed. Rio de Janeiro: Record, 2004.

SANTOS, Milton; SILVEIRA, Maria Laura. O Brasil: território e sociedade no início do século XXI. 7 ed. São Paulo: Record, 2005.

SANTOS, Milton. "O retorno do território". In: Território, globalização e fragmentação, (orgs) SANTOS, Milton; SOUZA, Maria Adélia Aparecida de; \& SILVEIRA, Maria Laura. São Paulo: Hucitec, 1996.

SINGER, Paul. Por uma economia politica da urbanização. São Paulo: Editora Contexto, 1998.

SOUTO de Oliveira, J. S. "Mutaçóes no Mundo do trabalho: o (triste) espetáculo da informalizaçáo". Revista Democracia Viva, 1(1), 8-12, 2004.

SPOSSATI, Aldaisa. Mapa da exclusãolinclusão social da cidade de São Paulo. São Paulo: EDUC, 1996.

SPOSITO, Eliseu Savério. "Sobre o conceito de território: um exercício metodológico para a leitura da formação territorial do sudoeste do Paraná”. In: 
RIBAS, A. D.; SPOSITO, E. S.; SAQUET, M. A. Território e desenvolvimento: diferentes abordagens. Francisco Beltrão: Unioeste, 2004.

THIOLLENT, Michel. Metodologia da pesquisa-ação. 10a. ed. São Paulo: Cortez, 2000.

VÉRAS, M. P. B. Trocando olhares : uma introdução à construçáo sociológica da cidade. São Paulo: Studio Nobel: EDUC, 2000.

VILLAÇA, F. Espaço intra-urbano no Brasil. São Paulo: Studio Nobel: FAPESP, 2001.

WIRTH, L. "Novos olhares sobre São Paulo: notas introdutórias sobre territórios, espaços e sujeitos da cidade mundial”. Revista Margem: Revisitando o Brasil, São Paulo: EDUC, 1997. 